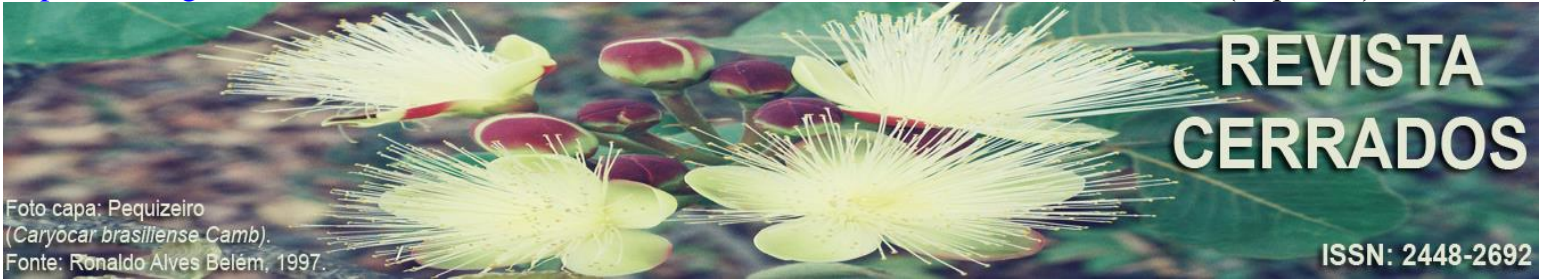

\title{
PARQUE ESTADUAL SERRA DO CABRAL EM MINAS GERAIS: classificação do grau de dificuldade da trilha do mirante
}

\section{SERRA DO CABRAL STATE PARK IN MINAS GERAIS: classification of the degree of difficulty of trilha do mirante}

\section{PARQUE ESTATAL SIERRA DE CABRAL EN MINAS GERAIS: clasificación del grado de dificultad del sendero del mirante}

\author{
Thiago Neves Silva \\ Universidade Estadual de Montes Claros - UNIMONTES, Montes Claros, \\ Minas Gerais, Brasil \\ E-mail: <thiagoturismo@gmail.com>. \\ Ricardo Henrique Palhares \\ Universidade Estadual de Montes Claros - UNIMONTES, Montes Claros, \\ Minas Gerais, Brasil \\ E-mail: <ricardo.palhares@ unimontes.br>.
}

\section{RESUMO}

A utilização de análise de informações para a construção de mapas temáticos se consolidou como um valioso instrumento para contribuir na gestão das áreas protegidas no Brasil. Os mapas auxiliam no planejamento e manejo dos parques e também como suporte informativo aos seus visitantes, principalmente para as trilhas disponíveis para uso público, onde se faz necessário oferecer aos visitantes orientações básicas para auxiliá-lo durante a sua visita, garantindo uma experiência segura e prazerosa. Nesse cenário, esse trabalho tem como objetivo identificar através das geotecnologias, o grau de dificuldade da Trilha do Mirante localizada no Parque Estadual Serra do Cabral-MG (PESC), usando como análise os critérios de declividade, estrutura do terreno, vegetação e drenagem. Como procedimentos metodológicos foram coletados dados de campo e trabalhados as variáveis definidas em ambiente SIG. A análise dos dados possibilitou a elaboração de cartas imagens temáticas conforme o grau de dificuldade da trilha.

Palavras-chaves: Turismo. Geotecnologias. Parque Serra do Cabral. Trilha do Mirante. 


\begin{abstract}
The use of information analysis for the construction of thematic maps has consolidated itself as a valuable tool to contribute to the management of protected areas in Brazil. The maps assist in the planning and management of the parks and as an informative support for its visitors, mainly for trails available for public use, where it is necessary to offer visitors basic guidelines to assist them during their visit, ensuring a safe and a pleasant experience. In this scenario, this study aims to identify through geotechnologies the degree of difficulty of Trilha do Mirante, located in the Serra do Cabral-MG State Park (SCSP), by using as analysis the criteria of slope, terrain structure, vegetation and drainage. As methodological procedures, field data were collected and the variables defined in the Geographic Information System (GIS) environment were worked on. The analysis of the data allowed the elaboration of thematic images maps according to the degree of difficulty of the trails.
\end{abstract}

Keywords: Tourism. Geotechnologies. Serra do Cabral State Park. Trilha do Mirante.

\title{
RESUMEN
}

La utilización de análisis de informaciones para la construcción de mapas temáticos se consolidó como un valioso instrumento para contribuir en la gestión de las áreas protegidas en Brasil. Los mapas auxilian en el plan y manejo de los parques y también como soporte informativo a sus visitantes, principalmente para los senderos disponibles para uso público, donde es necesario ofrecer a los visitantes orientaciones básicas para auxiliarlos durante su visita, garantizando una experiencia segura y placentera. En ese escenario, este trabajo tiene como objetivo identificar a través de las geotecnologías, el grado de dificultad del Sendero del Mirante, localizado en el Parque Estatal Sierra del Cabral-MG (PESC), usando como análisis los criterios de declividad, estructura del terreno, vegetación y drenaje. Como procedimientos metodológicos fueron colectados datos de campo y trabajadas las variables definidas en ambiente SIG. El análisis de los datos posibilitó la elaboración de cartas imágenes temáticas, de acuerdo al grado de dificultad de lo sendero.

Palabras-clave: Turismo. Geotecnologias. Parque Sierra de Cabral. Sendero del Mirante.

\section{INTRODUÇÃO}

No Brasil, os espaços instituídos legalmente para promover a proteção da natureza são chamados de unidades de conservação (UC) ou áreas protegidas. Eles são responsáveis pela preservação da biodiversidade e dos recursos naturais, auxiliando principalmente na manutenção dos seus ecossistemas e desempenhando também a função de habitat para as espécies e na manutenção das paisagens nativas presentes no espaço natural.

O atual Sistema Nacional de Unidades de Conservação da Natureza (SNUC) foi instituído pela Lei $\mathrm{n}^{0} 9.985$ de 18 de julho de 2000, regulamentando o artigo 225 da Constituição Federal. Conforme consta em seu artigo $3^{\circ}$ o SNUC é constituído pelo conjunto Revista Cerrados, Montes Claros/MG, v. 18, n. 02, p. 512-535, jul./dez.-2020. 
SILVA, T.N; PALHARES, R.H

Parque Estadual Serra do Cabral em Minas Gerais: classificação do grau de dificuldade da trilha do mirante

das Unidades de Conservação (UCs) federais, estaduais e municipais (BRASIL, 2000). O SNUC divide as UCs em dois grupos, com características específicas: as UCs de Proteção Integral - que admitem apenas o uso indireto dos seus recursos naturais, e as UCs Uso Sustentável - que buscam compatibilizar a conservação da natureza com o uso sustentável de parcela dos seus recursos naturais.

Dentre as diversas categorias de áreas protegidas existentes no território brasileiro, esse trabalho utilizou-se como espaço de estudo a categoria de Parque Estadual (PE), que são ambientes criados por decreto de Lei pertencente ao grupo de Proteção Integral, que permite o uso indireto dos seus recursos naturais, incluindo atividades de turismo e lazer (BRASIL, 2000).

No estado de Minas Gerais, as UCs são geridas pelo Instituto Estadual de Florestas (IEF), instituição fundada no ano de 1962 e vinculada a Secretaria de Estado de Meio Ambiente e Desenvolvimento Sustentável (SEMAD). No território mineiro, anteriormente a fundação do IEF, "políticos do governo já buscavam combater com o reflorestamento e também com o desmatamento" (IEF, 2009, p. 16).

Recomenda-se ressaltar que os parques estaduais foram constituídos inicialmente nas décadas de 1930 e 1940 no Sul e no Sudeste brasileiro, mas precisamente nos estados de Minas Gerais, São Paulo, Rio Grande do Sul e o Rio de Janeiro. "No presente momento, São Paulo e Minas Gerais simbolizam os estados que contem a maior parte das UCs em quantidade e extensão" (RYLANDS; BRANDON, 2005, p. 31).

Os parques são espaços de grandes áreas verdes e com belas paisagens, cachoeiras, trilhas, cavernas, sítios arqueológicos, localizadas em áreas naturais para propiciar a população uma opção de lazer onde cada indivíduo possa estabelecer interação com a natureza. É importante destacar que a população assuma também uma responsabilidade ética com o território apropriado, com preocupação à segurança e respeito ao meio ambiente.

As trilhas se apresentam como um dos principais meios para a realização dessas atividades em espaços naturais e de uma maneira particular, nos parques do estado, oferecendo como uma opção atrativa que além de auxiliar a proteção desses ambientes, propiciam o desenvolvimento da atividade turística e recreativa (COSTA, 2006). Conforme Andrade (2005) as trilhas são consideradas uma exclusiva opção de acesso as UCs e possibilitam a conexão com lugares e paisagens. 
Parque Estadual Serra do Cabral em Minas Gerais: classificação do grau de dificuldade da trilha do mirante

Abordar essas práticas do turismo em parques simboliza refletir como realizar uma atividade turística de maneira adequada nessas trilhas através do uso público em uma área de proteção integral. Logo, alguns aspectos são fundamentais e necessitam ser levados em consideração e não podemos esquecer que se refere a interações realizadas em territórios frágeis e que necessitam ser bem planejadas e geridas. Em seguida, outro ponto essencial é em relação aos turistas, isto é, os visitantes carecem de orientações de como se comportar em um ambiente protegido para garantir uma experiência segura e, sobretudo, agradável.

O trabalho consiste em uma abordagem de caráter qualitativo, envolvendo temas como: áreas protegidas (UCs), trilhas, uso público, visitação turística e geotecnologias na análise do espaço geográfico. Além disso, será utilizado uma seleção de critérios para estabelecer o grau de dificuldades da trilha do Mirante, tendo como referência o trabalho de Silva (2016) realizado no Parque Nacional do Itatiaia-RJ.

A partir do objeto exposto, o problema elaborado que direciona este artigo baseiase: como aplicação de uma classificação do grau de dificuldade de trilhas pode contribuir para o planejamento da visitação turística em áreas naturais protegidas, a partir da utilização de geotecnologias?

Para conceder um destaque nos questionamentos citados, o objetivo geral desse artigo é propor uma ferramenta de classificação da trilha do Mirante conforme o seu grau de dificuldade, levando em consideração alguns critérios como: Declividade, Vegetação, Estrutura do Terreno e Drenagem baseado em um estudo aplicado no PE Serra do CabralMG.

A relevância do tema da pesquisa proposta se justifica pelos poucos trabalhos científicos existentes sobre o assunto no contexto da Geografia, Turismo e áreas afins, além do mais, no Brasil os estudos de classificação de trilhas são incipientes e sobretudo, pela necessidade de um maior aprofundamento do assunto, pois, devido a subjetividade de critérios na classificação de trilhas, há muita divergência na discussão sobre o assunto.

\section{TURISMO E USO PÚBLICO EM UNIDADES DE CONSERVAÇÃO}

A procura pelo contato direto com a natureza tem como principal motivação a carência do individuo em estabelecer uma relação com o meio natural, em função da rotina agitada dos grandes centros urbanos, o turismo se apresenta de maneira atraente para 
SILVA, T.N; PALHARES, R.H

Parque Estadual Serra do Cabral em Minas Gerais: classificação do grau de dificuldade da trilha do mirante

promover essa relação intensa com a natureza, seja ela impulsionada para recarregar as baterias, por questões espirituais, para amenizar o estresse ou vivenciar novas experiências, entre outras (SERRANO; BRUHNS, 1997).

A respeito das vantagens do turismo em UCs, Takahashi (2004), destaca que essa atividade pode colaborar como uma potencialidade alternativa para a conquista dos propósitos de desenvolvimento e proteção de uma área. Em seguida, o quadro 1 destaca esses impactos positivos.

Quadro 1 - Benefícios da atividade turística em Unidades de Conservação

\begin{tabular}{|c|c|c|c|}
\hline \multirow{8}{*}{ ڤֶ, } & $\begin{array}{c}\text { Crescimento de possibilidades } \\
\text { econômicas }\end{array}$ & $\begin{array}{c}\text { Defesa do patrimônio cultural e } \\
\text { natural }\end{array}$ & Uma melhor qualidade de vida \\
\hline & $\begin{array}{l}\text { - incentiva novas empresas e amplia } \\
\text { a economia local }\end{array}$ & - defende os recursos ecológicos & $\begin{array}{l}\text { - promove os bens espirituais, } \\
\text { estéticos e de bem-estar }\end{array}$ \\
\hline & $\begin{array}{l}\text { - amplia as opções de empregos } \\
\text { para a comunidade local }\end{array}$ & $\begin{array}{l}\text { - preserva a biodiversidade e a } \\
\text { geodiversidade }\end{array}$ & $\begin{array}{l}\text { - incentiva a educação ambiental para } \\
\text { os visitantes e a comunidade local }\end{array}$ \\
\hline & $\begin{array}{l}\text { - aumento da geração de renda dos } \\
\text { envolvidos }\end{array}$ & $\begin{array}{l}\text { - contribui no desenvolvimento de } \\
\text { meios de financiamentos para a } \\
\text { unidade }\end{array}$ & $\begin{array}{l}\text { - estimula o desenvolvimento de } \\
\text { práticas culturais e artísticas }\end{array}$ \\
\hline & $\begin{array}{l}\text { - incentiva a manufatura de bens e } \\
\text { serviços locais }\end{array}$ & $\begin{array}{l}\text { - gera valores econômicos e defende os } \\
\text { recursos não percebidos pela } \\
\text { população local de outra maneira }\end{array}$ & $\begin{array}{l}\text { - amplia o nível de formação da } \\
\text { população local }\end{array}$ \\
\hline & - melhora o estilo de vida & $\begin{array}{l}\text { - repassa valores de proteção através } \\
\text { da educação e interpretação ambiental }\end{array}$ & $\begin{array}{l}\text { - incentiva a população a reconhecer } \\
\text { e valorizar o seu local e a sua cultura }\end{array}$ \\
\hline & $\begin{array}{l}\text { - contribui na capacitação dos } \\
\text { funcionários em novas atividades }\end{array}$ & $\begin{array}{l}\text { - incentiva as pesquisas científicas e } \\
\text { desenvolvimento de novos } \\
\text { procedimentos de manejo }\end{array}$ & $\begin{array}{l}\text { - Promove o intercambio cultural } \\
\text { entre a comunidade e os turistas } \\
\text { estrangeiros }\end{array}$ \\
\hline & $\begin{array}{l}\text { - Amplia a reserva de proteção da } \\
\text { unidade e da população local }\end{array}$ & & $\begin{array}{l}\text { - incentiva o aprendizado de outros } \\
\text { idiomas }\end{array}$ \\
\hline
\end{tabular}

Fonte: Takahashi (2004). Adaptado por HAMOY (2018)

A utilização pública é fundamental para contribuir na administração de uma UC, de maneira especial a do tipo parque. É por meio do fortalecimento do seu uso responsável, seguro e de mínimo impacto, que os gestores terão condições reais de por em ação as providências estabelecidas nos planos de manejo. Na prática, um Plano de Manejo, aponta a sistematização do entendimento referente ao aspecto físico e biológico de uma UC estabelecida e também as características ambientais, econômicas e sociais que fazem parte da unidade.

Segundo Vallejo (2015), a utilização pública de uma UC precisa ser compreendida como uma estratégia de reconhecimento social das próprias áreas protegidas. Com uma visão voltada para o parque, Pimentel (2013) estabelece que os assuntos referentes sobre o uso 
SILVA, T.N; PALHARES, R.H

Parque Estadual Serra do Cabral em Minas Gerais: classificação do grau de dificuldade da trilha do mirante público dos parques estão associados ao manejo socioambiental da UC, englobando características que ultrapassam os limites da mesma e devem colaborar no alcance significativo de conservação para a humanidade.

Contudo, ainda se faz necessário que na UC exista condições adequadas de infraestrutura física e de serviços, em harmonia com o ambiente natural, que auxilie com os propósitos de manejo. Como exemplos de infraestrutura, Kinker (2002), cita: centro de visitação equipado, estruturas de banheiro, opção de alojamento, entre outros; o autor ainda completa sobre o processo estrutural, a UC tenha um serviço de sinalização eficiente para orientar os visitantes, mapas, folheteria, fotografias, serviço de visitação guiada e um bom sistema de comunicação, dentre outros.

\section{TRILHAS E SISTEMA DE INFORMAÇÕES GEOGRÁFICAS}

A utilização de trilhas nas UCs beneficia uma maior proximidade do ser humano com o meio natural, oportunizando a realização de inúmeras atividades didáticas no contexto da Educação Ambiental (OLIVEIRA et al., 1999). As trilhas também podem ser indicadas como percursos estreitos, habitualmente não pavimentadas e intransitáveis para meios de veículos de passeio. Além disso, essas vias podem ser determinadas como caminhos, ou seja, itinerários que apresentam um momento de início e um encerramento preestabelecido para uma atividade turística (ABNT, 2008).

Logo, Andrade (2003) comenta que se o percurso é bem planejado, construído e com um manejo adequado, uma trilha pode auxiliar como ambiente de proteção aos possíveis efeitos referente ao uso do espaço e ao mesmo tempo, oferecer uma melhor condição de segurança, satisfação e conforto para os visitantes que optaram por uma atividade de ecoturismo.

Além das características, outro aspecto fundamental para o processo de planejamento de uma trilha é em relação a sua classificação. Hugo (1999) chama atenção para a necessidade de classificação dessas trilhas conforme seu nível de dificuldade, de maneira a transformá-la em uma atividade com mais segurança. Já Cotes et al. (2007) mencionam ser subjetivos as definições sobre o conteúdo presente em periódicos e revistas especializadas, inapropriados para prestar informações ao público que usufrui dessas atividades. 
SILVA, T.N; PALHARES, R.H

Parque Estadual Serra do Cabral em Minas Gerais: classificação do grau de dificuldade da trilha do mirante

Os Sistemas de Informações Geográficas (SIG) são propostos para o tratamento de informações geográficas, abrangendo os processos de aquisição de dados, seu armazenamento, análise e manipulação, com o uso de ferramentas, programas computacionais e com a participação de pessoas especializadas (FERREIRA, 2006; CÂMARA et al., 2001).

Nessa definição, o SIG consiste em sistemas que tratam de informações geográficas, e segundo Miranda (2010, p. 23) esclarece:

No SIG, a realidade é representada (modelada) como uma série de elementos geográficos definidos de acordo com dois atributos de dados. $\mathrm{O}$ elemento de dado geográfico (o dado espacial) é usado para providenciar uma referência para o elemento de dado atributo (o dado não espacial).

A utilização do SIG em trabalhos geográficos e em outras áreas teve um grande crescimento nas últimas décadas e se tornou uma importante ferramenta para representação, aquisição e análise de dados referente ao espaço geográfico (DAMBRÓS, 2020). Segundo Florenzano (2005, p. 24) "as geotecnologias associados aos Sistemas de Informações Geográficas e ao Sensoriamento Remoto, encontram-se gradativamente mais relacionados". Suas práticas nos diversos ambientes do conhecimento têm aumentado a cada ano. Já Martinelli (2008) comenta que com essas tecnologias, a cartografia foi avançando até evoluir praticamente para um Sistema de Informações Geográficas (SIG), em que elaborar mapas tornou-se um processo mais dinâmico.

A aplicação dos SIG ao Turismo na Natureza desenvolvida nesta investigação reporta-se à gestão e/ou modelação da atividade de pedestrianismo. Ainda que o número de estudos sobre esta matéria em particular seja ainda reduzida, podem enumerar-se alguns (OSÓRIO, 2010). Outro aspecto importante é o crescimento da utilização das ferramentas do SIG para auxiliar no planejamento e gestão dos parques, como é o caso do Parque Estadual Serra do Cabral (PESC), com destaque nos processos do uso público.

\section{CARACTERIZAÇÃO DA ÁREA DE ESTUDO}

O PESC, local escolhido para a realização desse trabalho, recebe o mesmo nome da Serra e está situado entre os Municípios de Buenópolis e Joaquim Felício, englobando uma área de 24.494,1728 ha, sendo que dessa área total, 64\% pertence a cidade de Buenópolis e $36 \%$ no seu território encontra-se cidade de Joaquim Felício, como demonstrada no mapa 
SILVA, T.N; PALHARES, R.H

Parque Estadual Serra do Cabral em Minas Gerais: classificação do grau de dificuldade da trilha do mirante abaixo. O PESC se apresenta como uma UC de proteção integral e foi constituída a partir do decreto de Lei Estadual no 44.121, reconhecido no dia 29 de setembro de 2005.

Figura 1 - Mapa de localização do PE Serra do Cabral-MG

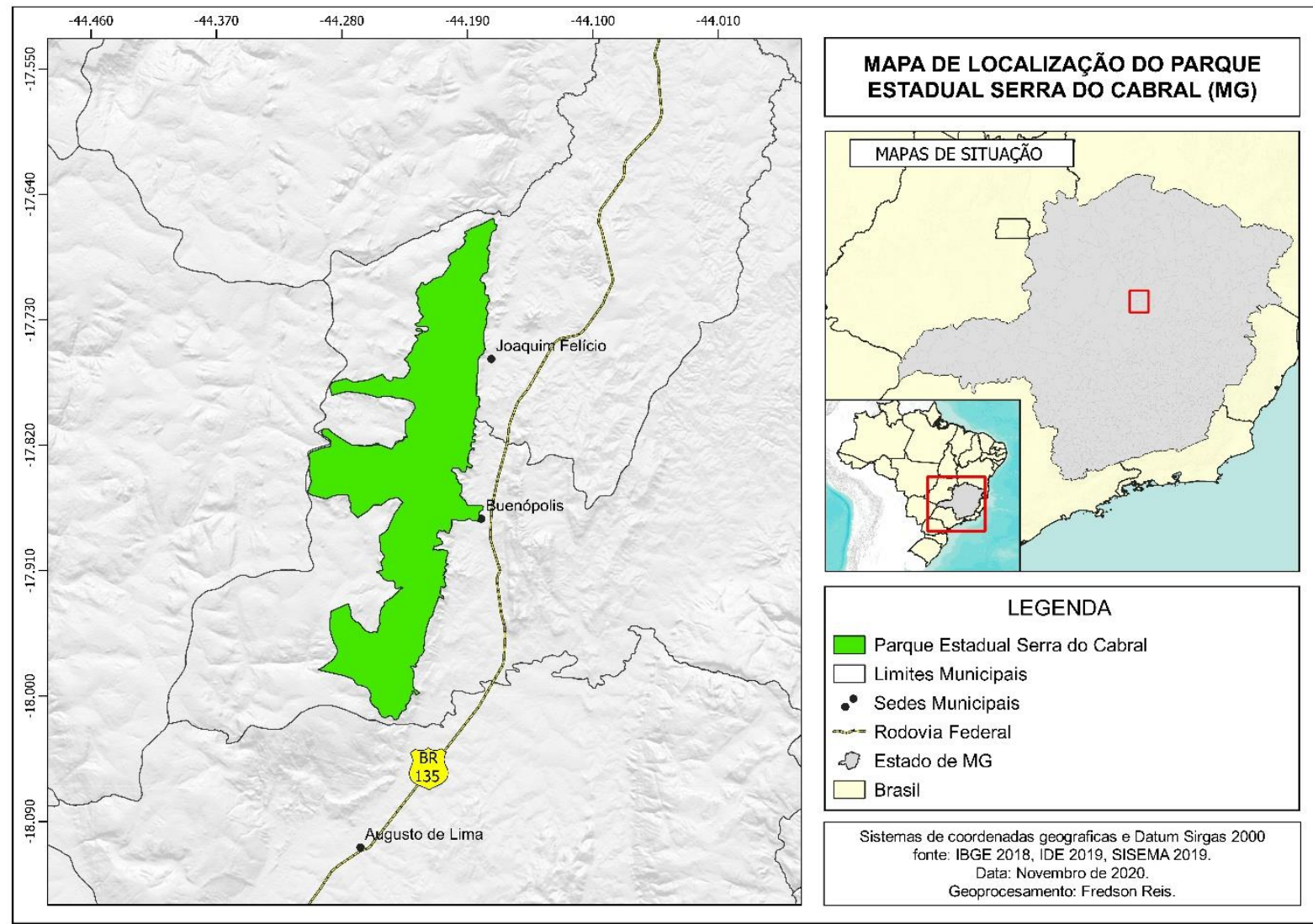

Fonte: IBGE, 2018.

O PESC possui significativa importância ambiental e histórico-cultural, principalmente por proteger extensos e contínuos ambientes naturais, os quais incluem nascentes formadoras de importantes rios e córregos da bacia do Rio São Francisco. E, também, um mosaico de vegetação muito variada, que inclui cerrado, campos limpos, campos sujos, matas ciliares, além da fauna associada, com elevada diversidade de espécies (IEF, 2013).

Com todos estes aspectos, o PESC tem como objetivo incentivar a pesquisa científica, incentivar o turismo, promover e desenvolver o Uso Público com participação social, envolvendo os municípios e as comunidades da região, aproveitando e valorizando as 
SILVA, T.N; PALHARES, R.H

Parque Estadual Serra do Cabral em Minas Gerais: classificação do grau de dificuldade da trilha do mirante

belezas cênicas da área, bem como estimular a conservação e o manejo racional dos recursos naturais (IEF, 2013).

No que se refere à vegetação, a área do PESC e seu entorno situam-se no domínio fitogeográfico do cerrado. De forma geral, o cerrado é conceituado como uma vegetação xeromorfa (que vive em condições de baixa disponibilidade de água), com árvores de aspecto tortuoso, preferencialmente de clima estacional, mas podendo também ser encontrado sob com maior disponibilidade hídrica (IEF, 2013).

O PESC possui ainda belos campos rupestres com afloramentos rochosos que são caracterizados pelos campos arenosos, campos pedregosos e campos brejosos. O campo rupestre é considerado um sistema de Refúgio Vegetacional pois apresenta uma vegetação diferenciada tanto nos aspectos florístico quanto fisionômico-ecológico da flora dominante da região.

Outra característica muito importante na área do PESC, são suas belas Veredas distribuídas ao longo do seu território e que representa uma ótima opção de atrativo para os seus visitantes. As veredas são áreas de extrema importância para a conservação e são consideradas Área de Preservação Permanente. Na área do PESC, ela ocorre nas partes superiores do relevo ocupando vastas áreas planas acompanhando os cursos d'água (IEF, 2013).

Na parte sul do Parque, as drenagens vertem nas direções do Córrego das Pedras e para onde ele flui, o Riacho Fundo, que é afluente do Rio Curimataí, localizado ao sul da área enfocada, e que constitui um afluente do Rio das Velhas. O Rio das Velhas é afluente de primeira ordem do Rio São Francisco e, nele deságua cerca de $15 \mathrm{~km}$ ao sul da foz do Rio Jequitaí (IEF, 2013).

Outra característica singular no PESC é seu potencial arqueológico, que no parque esse patrimônio é caracterizado principalmente através das pinturas rupestres deixadas pelos primeiros habitantes da região, antes mesmo da colonização portuguesa. Dentre os principais registros arqueológicos da área do parque, destacam-se: Lapa da Pedra Alta, Lapa dos Símbolos, Lapa da Onça, Ponte de Terra, Lapa do Quati, Lapa Escrita, Pedra Escrita, Lapa da Bela Vista, Lapa do Buriti, Lapa do Pau D’óleo, Lapa da Mata os Vianas e a Lapa do Pau Terra (IEF, 2013).

Dentre os atrativos existentes no parque, a Trilha do Mirante foi a selecionada para a realização do trabalho e atualmente, é considerada o atrativo mais visitado do Parque. 
SILVA, T.N; PALHARES, R.H

Parque Estadual Serra do Cabral em Minas Gerais: classificação do grau de dificuldade da trilha do mirante

Sua localização próxima ao perímetro urbano da cidade de Buenópolis e a facilidade de acesso, contribuem para esse cenário. Toda a sua extensão (ida e volta) tem aproximadamente $3,7 \mathrm{~km}$ de distância.

A sede do PESC marca o início e o final da trilha e dentre as infraestruturas citadas, podemos destacar, placas de sinalização, passarelas de madeira, construção de barreiras chamadas popularmente de passa um, com o objetivo de evitar outros meios de acesso a trilha que não seja pela caminhada e por fim, um deque de madeira com bancos no ponto mais alto da trilha, que oferece um conforto ao visitante e permite desfrutar com segurança de uma bela vista panorâmica da cidade.

\section{PROCEDIMENTOS METODOLÓGICOS}

Observando algumas referências de trabalhos, percebeu-se que métodos utilizados para o planejamento e a classificação do grau de dificuldades de trilhas estão em fases iniciais, isto é, necessitam de mais aprofundamentos, resultando na ausência de parâmetros mais objetivos no processo de classificação das trilhas. Contudo, essa pesquisa utilizou-se como referência os trabalhos de (MAGRO, 1999; HUGO, 1999; ANDRADE, 2003; TAKAHASHI, 2004; COSTA, 2006; e SILVA, 2016).

O trabalho foi desenvolvido em três etapas, revisão bibliográfica, coleta de dados em campo e elaboração das cartas imagens referente ao grau de dificuldade da Trilha do Mirante. Esse trabalho ainda dispõe-se na classificação do grau de dificuldade de trilhas atendendo alguns indicativos biofísicos, baseado no trabalho de Silva, Panchaud e Lima (2016), e adaptado por Silva (2016) desenvolvido no Parque Nacional de Itatiaia (PNI), com o propósito de diminuir a escala de subjetividade do levantamento. Além disso, os parâmetros e tipos de dificuldades contaram como base outros estudos como EMBRAPA (1979), Salomão (1999), Magro (1999), Costa (2006), Argentina (2010), e FEMERJ (2016), com a intenção de ser aplicado em outros lugares (Parques) e não exclusivamente no PNI.

Os indicativos escolhidos para a classificação foram: vegetação, declividade, estrutura do terreno e drenagem. Todos os critérios de forma individual foram simbolizados por um tema, isto é, recebeu uma base de informação que equivale a uma série de aspectos espaciais sendo estabelecida como um suporte de informações georreferênciadas no SIG. 
SILVA, T.N; PALHARES, R.H

Parque Estadual Serra do Cabral em Minas Gerais: classificação do grau de dificuldade da trilha do mirante

Vegetação: a vegetação foi utilizada para determinar em qual trecho da trilha o visitante estará mais exposto ao sol, estabelecendo que quanto maior a cobertura vegetal ao longo do percurso, o deslocamento será mais confortável e terá uma sensação térmica devido à sombra mais agradável, composta por quatro características: cobertura vegetal alta, média, baixa e sem vegetação, distribuída em alta (muito fácil), com valor 1, média (fácil), com valor 2, baixa (moderada), com valor 3 e trecho sem vegetação (difícil), com valor 4 .

Declividade: foi utilizado como referências de parâmetros a metodologia da Embrapa (1979), adaptado por Salomão (1999) que classifica a sua declividade através de um intervalo e possui uma variação entre 1,1 a 15,1, distribuídos em classes sendo, plano, suave ondulado, ondulado e forte ondulado, que recebem uma reclassificação e valores conforme o seu grau de declividade: muito fraca, valor 2 , fraca, valor 3 , média, valor 4 e forte, valor 5 . No indicativo referente a declividade, foi definido uma nota de 2 a 5 , e durante o processo de validação dos dados esse critério foi reclassificado conforme o grau de dificuldade, entre fácil a muito difícil, como recurso para permitir as intervenções do SIG.

Estrutura do Terreno: No aspecto do terreno, a sua classificação estão associadas ao campo percorrido pelo visitante na trilha, isto é, a existência de barreiras pode influenciar no deslocamento e também no grau de dificuldade, ocasionando um maior esforço ao caminhante e deixando uma situação de insegurança durante percurso.

Os parâmetros utilizados nesse campo tiveram como referência os trabalhos realizados pela Federação de Montanhistas e Escaladores do Rio de Janeiro (FEMERJ, 2016), no Brasil e da Huella Andina, na Argentina (2010), adaptado e utilizado por Silva (2016). A classificação desse critério se estabelece como superfície lisa, sendo uma parte da trilha fácil, com valor 2, superfície com poucos obstáculos, moderado e com valor 3, com muitos obstáculos, difícil e com valor 4, e por fim, superfície muito irregular/trechos com ascensão, ou seja, com necessidade de escalada, sendo muito difícil e com valor 5.

Drenagem: Conforme o estudo de Magro (1999), a drenagem é um dos parâmetros aplicados para avaliar os efeitos físicos e biológicos da trilha, atentando de maneira visual a presença ou ausência da quantidade de água no solo. Portanto, uma drenagem lenta ou ruim é classificada conforme o acúmulo de água no terreno e apresente a formação de charcos e áreas alagadiças. Para esse critério, foi observado algumas características, sendo drenagem natural rápida, sendo fácil e com valor 2 ou drenagem natural lenta ou impedida, sendo moderado e com valor 3. Para o Parque Serra do Cabral esse critério 
SILVA, T.N; PALHARES, R.H

Parque Estadual Serra do Cabral em Minas Gerais: classificação do grau de dificuldade da trilha do mirante

é muito importante, pois algumas trilhas estudadas nesse trabalho possuem trechos com a presença de riachos e veredas e dependendo da situação, poderá também exercer influência no deslocamento.

Para a coleta de informações foi utilizado uma ficha de campo conforme tabela 1 , que contempla os elementos necessários para uma análise da trilha propostos pela pesquisa dentro dos critérios: vegetação, declividade, estrutura do terreno e drenagem.

Tabela 1 - Modelo Ficha de Campo - Coleta de dados

\begin{tabular}{|c|c|c|c|c|c|c|c|c|c|c|}
\hline PONTO & L.AT. & LONG. & $\underset{(\mathrm{m})}{\text { ALT. }}$ & $\begin{array}{l}\text { DIST. } \\
\text { (m) }\end{array}$ & Descriçầ & $\begin{array}{c}\text { Declividade } \\
\text { (\%) }\end{array}$ & Classe & $\begin{array}{l}\text { Estru. } \\
\text { Terremo }\end{array}$ & Vegetaçlo & Drenagem \\
\hline 1 & 8024530 & 586423 & 595 & 0 & Sede do PESC & - & - & - & - & - \\
\hline 2 & 8024595 & 586506 & 593 & 121 & Fundo da Sede & 1,7 & suave & $\begin{array}{l}\text { superficie } \\
\text { lisa }\end{array}$ & baixa & $\begin{array}{l}\text { Natural } \\
\text { rápida }\end{array}$ \\
\hline 3 & 8024663 & 586485 & 592 & 87 & Ponto Brejimho & 1.1 & suave & $\begin{array}{l}\text { superficie } \\
\text { lisa }\end{array}$ & media & $\begin{array}{l}\text { Natural } \\
\text { rạpida }\end{array}$ \\
\hline 4 & 8024782 & 586480 & 598 & 120 & $\begin{array}{l}\text { Passarela de } \\
\text { Madeira }\end{array}$ & 5,0 & suave & $\begin{array}{c}\text { superficie } \\
\text { lisa }\end{array}$ & baixa & $\begin{array}{l}\text { Natural } \\
\text { rápida }\end{array}$ \\
\hline 5 & 8024963 & 586424 & 617 & 191 & $\begin{array}{l}\text { Ponte de } \\
\text { Madeira }\end{array}$ & 9,9 & ondulado & $\begin{array}{l}\text { superficie } \\
\text { lisa }\end{array}$ & 5/vegetaçào & $\begin{array}{l}\text { Natural } \\
\text { rạpida }\end{array}$ \\
\hline 6 & 8025059 & 586264 & 624 & 184 & $\begin{array}{l}\text { Drenagem } \\
\text { pequena }\end{array}$ & 3.8 & ondulado & $\begin{array}{l}\text { superficie } \\
\text { lisa } \\
\end{array}$ & 5/vegetaçào & $\begin{array}{c}\text { Sem } \\
\text { dreangem }\end{array}$ \\
\hline 7 & 8025089 & 585996 & 640 & 349 & $\begin{array}{c}\text { Estrada } \\
\text { (veículos) }\end{array}$ & 4,6 & ondulado & $\begin{array}{l}\text { superficie } \\
\text { lisa }\end{array}$ & 5 /vegetaçào & $\begin{array}{c}\text { Sem } \\
\text { dreangem }\end{array}$ \\
\hline 8 & 8025180 & 585761 & 672 & 337 & Aces5o Mirante & 9.5 & ondulado & $\begin{array}{c}\text { pouco } \\
\text { obstáculo }\end{array}$ & 5/vegetaçào & $\begin{array}{c}\text { Sem } \\
\text { drenagem }\end{array}$ \\
\hline 9 & 8025515 & 585450 & 742 & 494 & Placa Mirante & 15,1 & ondulado & $\begin{array}{c}\text { pouco } \\
\text { obstaculo }\end{array}$ & s/vegetaçào & $\begin{array}{c}\text { Sem } \\
\text { dreangem }\end{array}$ \\
\hline 10 & 8025439 & 585570 & 757 & 154 & Mirante & 9.7 & ondulado & $\begin{array}{c}\text { pouco } \\
\text { obstáculo }\end{array}$ & s/vegetaçào & $\begin{array}{c}\text { Sem } \\
\text { drenagem }\end{array}$ \\
\hline 11 & 8025019 & 585863 & 654 & 827 & $\begin{array}{c}\text { Estrada } \\
\text { (veiculos) - } \\
\text { retorno }\end{array}$ & 12,5 & ondulado & $\begin{array}{l}\text { pouco } \\
\text { obstáculo }\end{array}$ & 5/vegetaçào & $\begin{array}{c}\text { Sem } \\
\text { drenagem }\end{array}$ \\
\hline 12 & 8024502 & 586435 & 616 & 844 & $\begin{array}{l}\text { Sede do PESC } \\
\text { - Fim da Trilla }\end{array}$ & 4.5 & suave & $\begin{array}{l}\text { superficie } \\
\text { lisa }\end{array}$ & 5/vegetaçào & $\begin{array}{c}\text { Sem } \\
\text { drenagem }\end{array}$ \\
\hline
\end{tabular}

Fonte: Elaborado pelos autores.

No processo da coleta de dados foi utilizado um aparelho GPS modelo Garmin, que permite uma leitura via Satélite das informações. Os pontos de referência contidos nos mapas foram elaborados conforme as características de cada percurso, isto é, a medida que observava-se uma mudança nos aspectos do trajeto. Em todo o percurso da trilha o registro aconteceu de forma automática pelo sistema de gravação das coordenadas e ao mesmo tempo em pontos estratégicos houve uma marcação conforme a necessidade de dados mais específicos associados aos critérios estudados, o que contribuiu para o processo de interpretação das informações pelo SIG. 
SILVA, T.N; PALHARES, R.H

Parque Estadual Serra do Cabral em Minas Gerais: classificação do grau de dificuldade da trilha do mirante

Além do registro dos pontos, também possibilitou a marcação da distância total do trajeto. Para o processo de elaboração das cartas imagens, o trabalho utilizou uma sequência básica destinada para um projeto em SIG, contemplando inicialmente a entrada das informações, depois o processamento dessas informações e em seguida, a etapa de saída desses dados. Todo esse sistema operacional estabeleceu uma relação com as camadas dessas informações, para a construção da carta imagem final, referente ao grau de dificuldade da Trilha do Mirante.

$\mathrm{Na}$ etapa de entrada de dados foi utilizado um aparelho de GPS para coletar as informações e descarregadas posteriormente para a realização do processo de traçado da trilha e dos pontos em destaque. Logo em seguida, esses dados foram transferidos para o Google Earth com o propósito de visualizar o traçado da trilha sobreposta a uma imagem de satélite.

Para o processamento das informações, os dados levantados foram manipulados e usados para a construção das cartas imagens, e posteriormente, esses dados foram reclassificados e calculados utilizando o recurso de álgebra de mapas, que posteriormente foram validados conforme os graus de dificuldades descritos anteriormente (muito fácil - 1, fácil - 2, moderado -3, difícil -4).

E por fim, a etapa de saída dos dados está composta pela conclusão de dois produtos finais: primeiro as cartas imagens individuais conforme cada indicativo (declividade, vegetação, estrutura do terreno e drenagem) e o outro produto foi a carta imagem da trilha, apresentando o seu grau de dificuldades distribuídas por trajetos e cores, e categorizado como muito fácil, fácil, moderado e difícil (EMPRAPA, 1979).

\section{RESULTADOS E DISCUSSÕES}

Para a elaboração do mapa de declividade da respectiva trilha foram registradas as altimetrias do ponto inicial e final de cada trecho demarcado, além da distância percorrida entre os pontos através do aparelho GPS. Em seguida esses dados foram exportados para o Google Earth para uma melhor visualização do percurso pela imagem de satélite.

Considerando as classes de declividade do percurso, observou-se que esse terreno possui vários trechos com declividade abaixo de $8 \%$, que favorecem a caminhada, porém, na parte final da trilha, precisamente no ponto 10, possui um trecho acima de $15 \%$ com 757 
SILVA, T.N; PALHARES, R.H

Parque Estadual Serra do Cabral em Minas Gerais: classificação do grau de dificuldade da trilha do mirante

metros de altitude e aproximadamente, 494 metros de distância, provocando nesse trecho um maior esforço físico ao visitante.

A maioria do percurso apresentou uma diferença entre 592 e 672 metros de altitude, demonstrando que a trilha possui uma baixa declividade na maioria do trajeto, entre o início do trajeto localizado na Sede Administrativa do PESC até próximo ao acesso da estrada de veículos. Após o processamento dos dados, foi elaborado a carta imagem de declividade, utilizando um conjunto de cores (verde, amarelo, laranja e vermelho), conforme figura 2 demonstrando a variação de declividade entre os doze pontos demarcados.

Figura 2 - Carta Imagem: Declividade

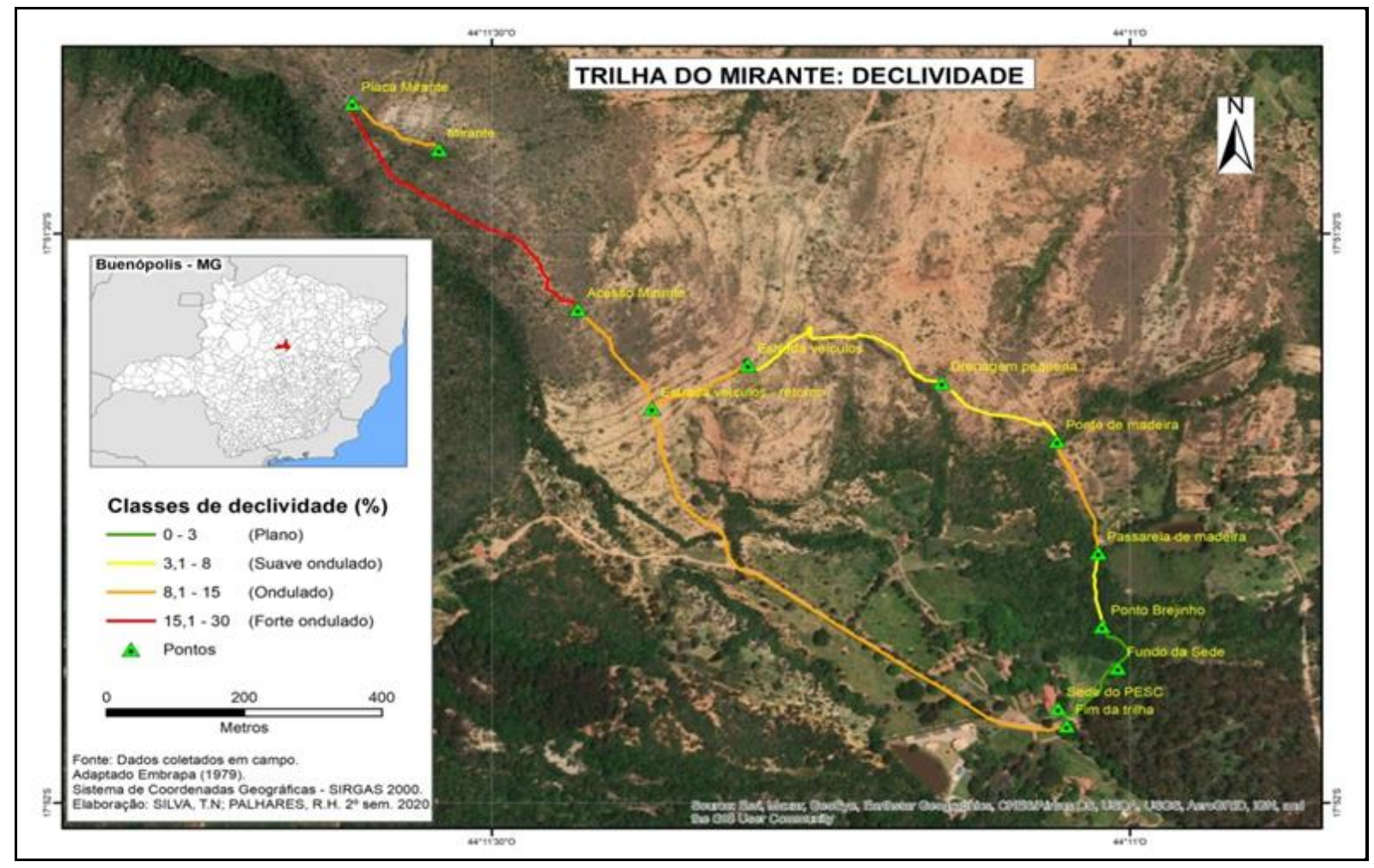

Fonte: Elaborado pelos autores.

Além disso, foi possível classificar através de uma fórmula matemática (regra de três) somando as distâncias entre os pontos, dividido por 100 e multiplicado pela distância total da trilha, $(3,7 \mathrm{~km})$, a porcentagem da classe total do percurso, sendo: $46 \%$ do percurso se encontra na classe de plano e suave ondulado, $40 \%$ na classe ondulado e $14 \%$ na classe forte ondulado. 
SILVA, T.N; PALHARES, R.H

Parque Estadual Serra do Cabral em Minas Gerais: classificação do grau de dificuldade da trilha do mirante

No processo de elaboração da carta imagem referente à estrutura do terreno, foi utilizado como referência os critérios de classificação observados durante o levantamento de dados em campo, sinalizando o tipo de superfície da trilha e registrando os pontos no GPS. Logo após o reconhecimento das características do terreno, foi realizado a reclassificação conforme os valores e o grau de dificuldade estabelecidos na metodologia.

A trilha do Mirante possui dois tipos de superfície predominantes que definem a estrutura do seu terreno. Na parte inicial da trilha é observado um trecho de aspecto liso e de fácil deslocamento para o visitante (Figura 3). Já na parte final do percurso por apresentar um trecho mais rochoso, observa-se um terreno ondulado e com poucos obstáculos (Figura 4).

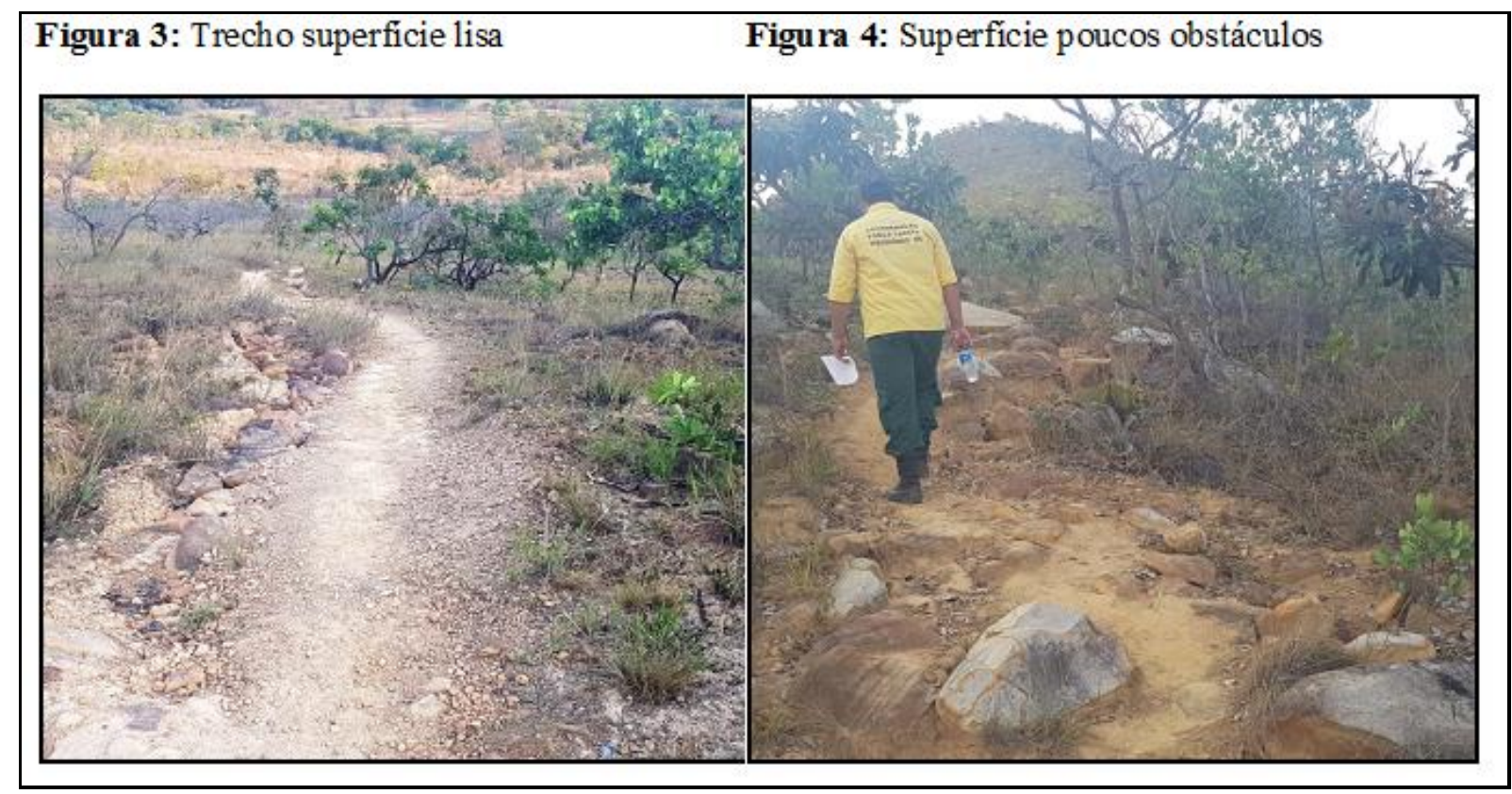

Fonte: Acervo dos autores.

Pela imagem de satélite do Google Earth representada na carta imagem (figura 5) é possível visualizar as condições do grau de dificuldade do percurso através de cores entre os pontos que retratam as caraterísticas específicas de todo o trajeto da trilha percebendo que a maior parte do trajeto, $52 \%$ é composto por um piso de superfície lisa e $48 \%$ composto por uma superfície com poucos obstáculos. Além disso, mesmo na parte com o piso contendo poucos obstáculos é possível realizar um deslocamento seguro sem a necessidade de uma estrutura física obrigatória, como guarda de mão, escadas, entre outras. 
SILVA, T.N; PALHARES, R.H

Parque Estadual Serra do Cabral em Minas Gerais: classificação do grau de dificuldade da trilha do mirante

Figura 5 - Carta Imagem: Estrutura do Terreno

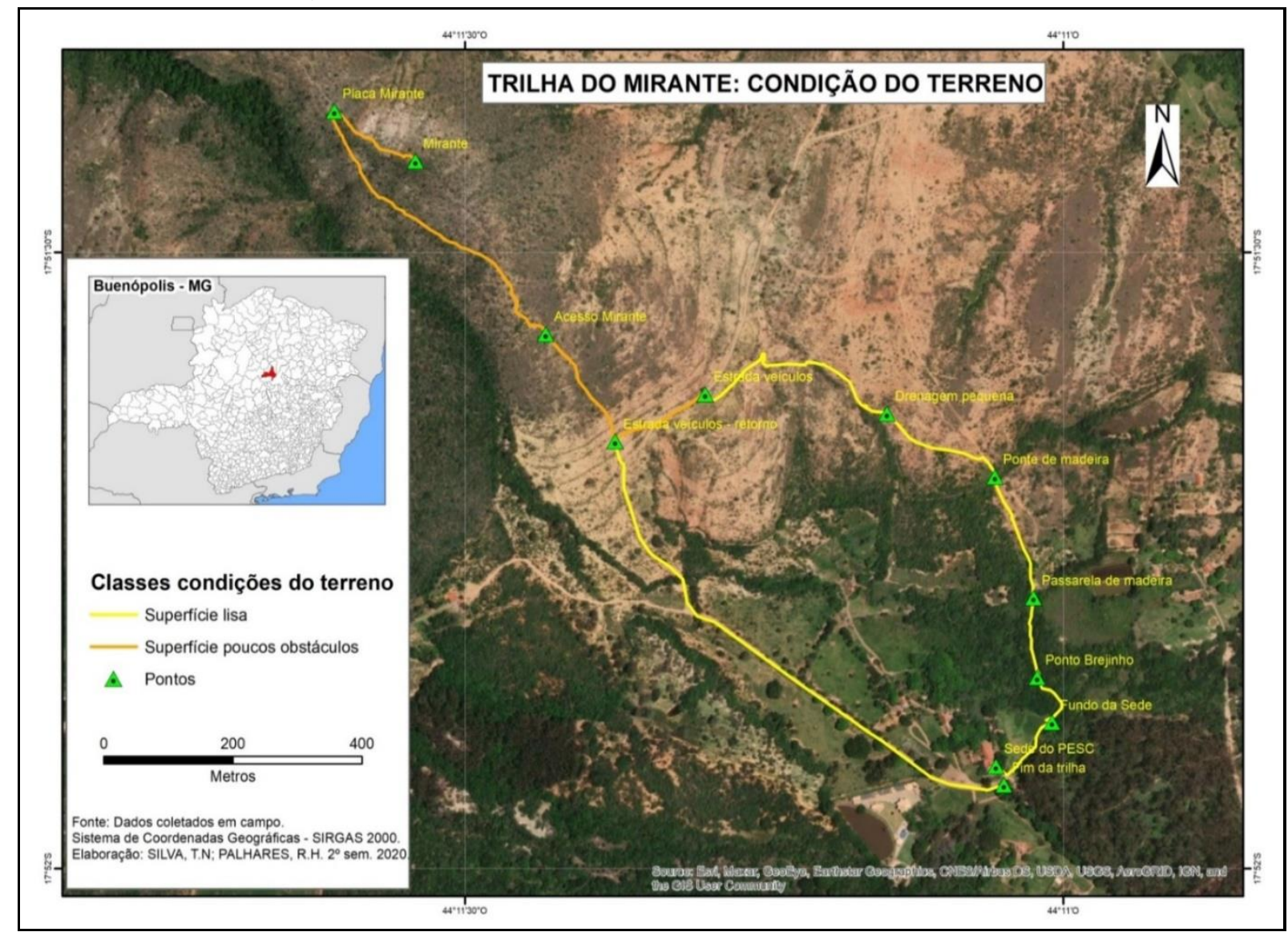

Fonte: Elaborado pelos autores.

$\mathrm{Na}$ elaboração da carta imagem da Vegetação utilizou-se a mesma dinâmica atribuída para os outros indicativos. Durante o levantamento de campo foi observado entre os pontos as características da cobertura vegetal e registrando essas variações com o GPS. Logo em seguida, os dados foram exportados para o Google Earth com a imagem de Satélite para melhor visualizar a distribuição das informações.

Em seguida, o trajeto foi marcado com traços e cores distintos entre as três possíveis variações, conforme definido na metodologia, e por fim foi classificado o grau de dificuldade associado com a vegetação na trilha. Durante o processo de classificação da trilha, realizou-se a fórmula matemática (regra de três) utilizada anteriormente entre a distância dos pontos multiplicado por 100 e dividido pela distância total da trilha.

Foi possível concluir que quase a totalidade do percurso, ou seja, $90 \%$ apresenta uma classe de sem vegetação, tendo ainda $7 \%$ de vegetação média e apenas $3 \%$ de vegetação baixa, conforme as imagens abaixo. 
SILVA, T.N; PALHARES, R.H

Parque Estadual Serra do Cabral em Minas Gerais: classificação do grau de dificuldade da trilha do mirante

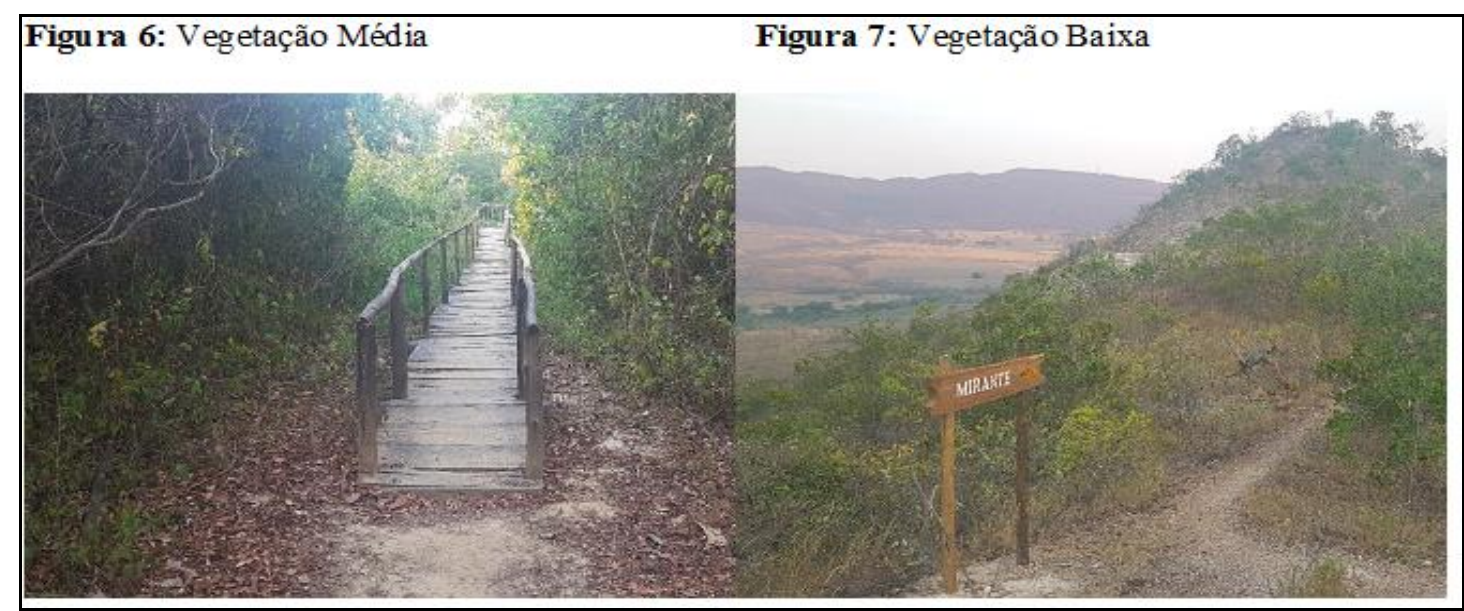

Fonte: Acervo dos autores.

Contudo, de acordo com a carta imagem da vegetação (figura 8) é possivel perceber que praticamente em todo o percuso o visitante estará sem cobertura vegetal e diretamente exposto ao sol, o que aumenta o grau de dificuldade da trilha, principalmente nos pontos com a maior altitude.

Figura 8 - Carta Imagem: Vegetação

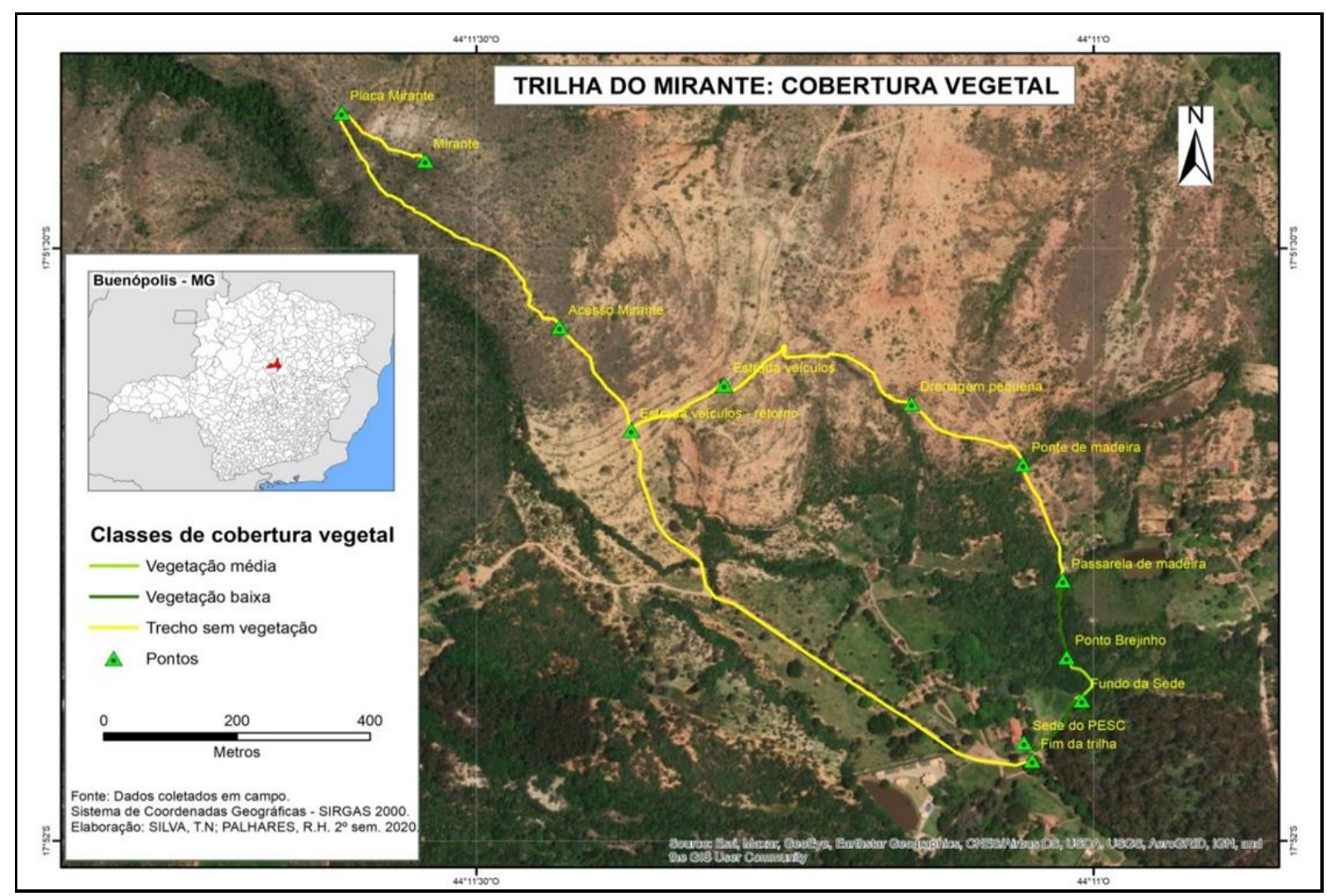

Fonte: Elaborado pelos autores.

Revista Cerrados, Montes Claros/MG, v. 18, n. 02, p. 512-535, jul./dez.-2020. 
SILVA, T.N; PALHARES, R.H

Parque Estadual Serra do Cabral em Minas Gerais: classificação do grau de dificuldade da trilha do mirante

No caso específico da drenagem, foi utilizado também o método de observação durante o levantamento de dados e em quais pontos existiam a presença de cursos d'água e qual a sua influência no trajeto para o visitante. Utilizou-se também o GPS para marcação do trajeto e assim foi possível registrar os pontos para serem utilizados da etapa de processamento dos dados.

Durante o processo de formatação dos dados, foi usado novamente a imagem de Satélite do Google Earth para exposição do percurso utilizando o traçado com cores e a apresentação do trajeto com a presença de água distribuídas durante a trilha. Foi possível observar que a presença de drenagem ocorre na parte inicial do percurso, ou seja, entre os pontos 3,4,5,6 e 7. Porém, apenas nos pontos 3, 45 e 6 existe a presença de água conforme as imagens abaixo.

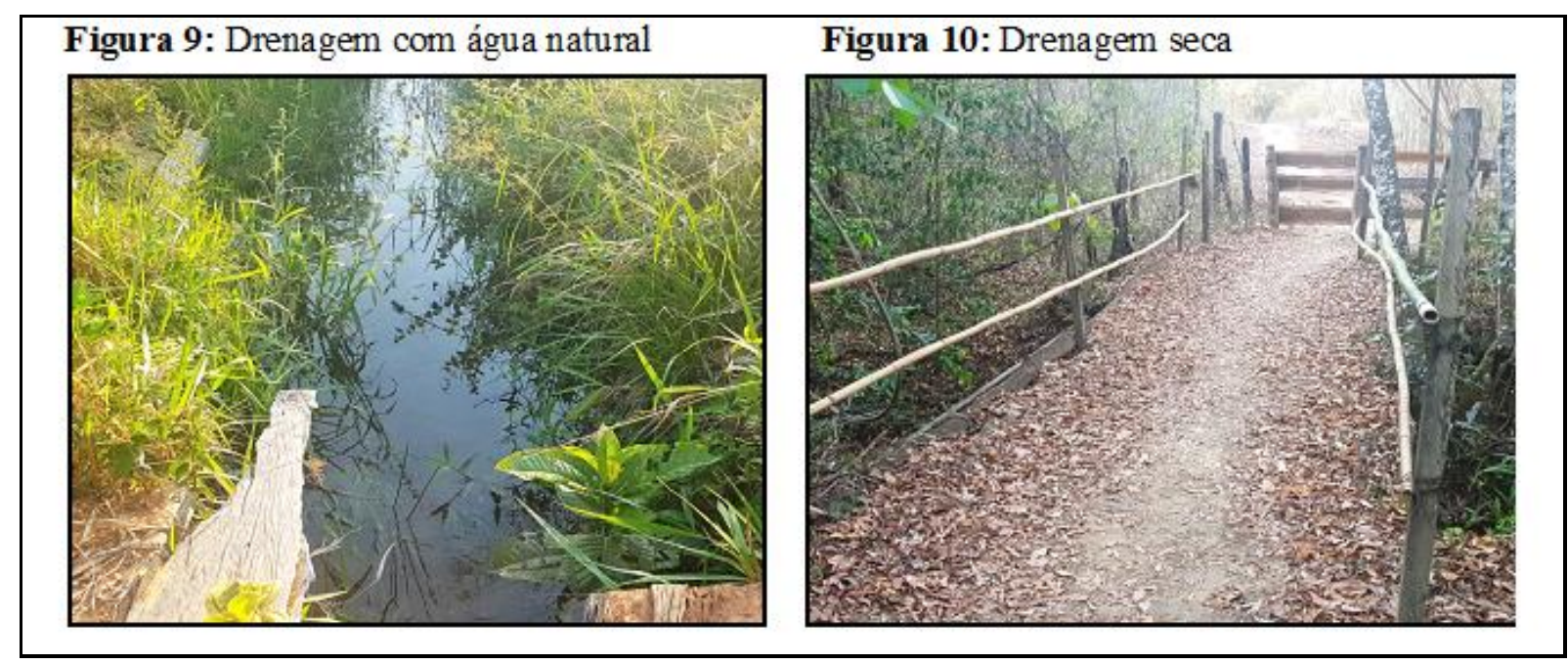

Fonte: Acervo do autor

Portanto é possível concluir após a realização da fórmula matemática (regra de três) utilizado também para os outros critérios, que a maior parte do percurso, $84 \%$ da trilha do Mirante não possui a presença de drenagem e apenas 16\% (Figura 11), apresenta a característica de drenagem, uma parte com água e outra seca. Importante destacar que nos pontos com a presença de água, existem estruturas de pontes para facilitar o deslocamento dos visitantes. 
SILVA, T.N; PALHARES, R.H

Parque Estadual Serra do Cabral em Minas Gerais: classificação do grau de dificuldade da trilha do mirante

Figura 11 - Carta Imagem: Drenagem

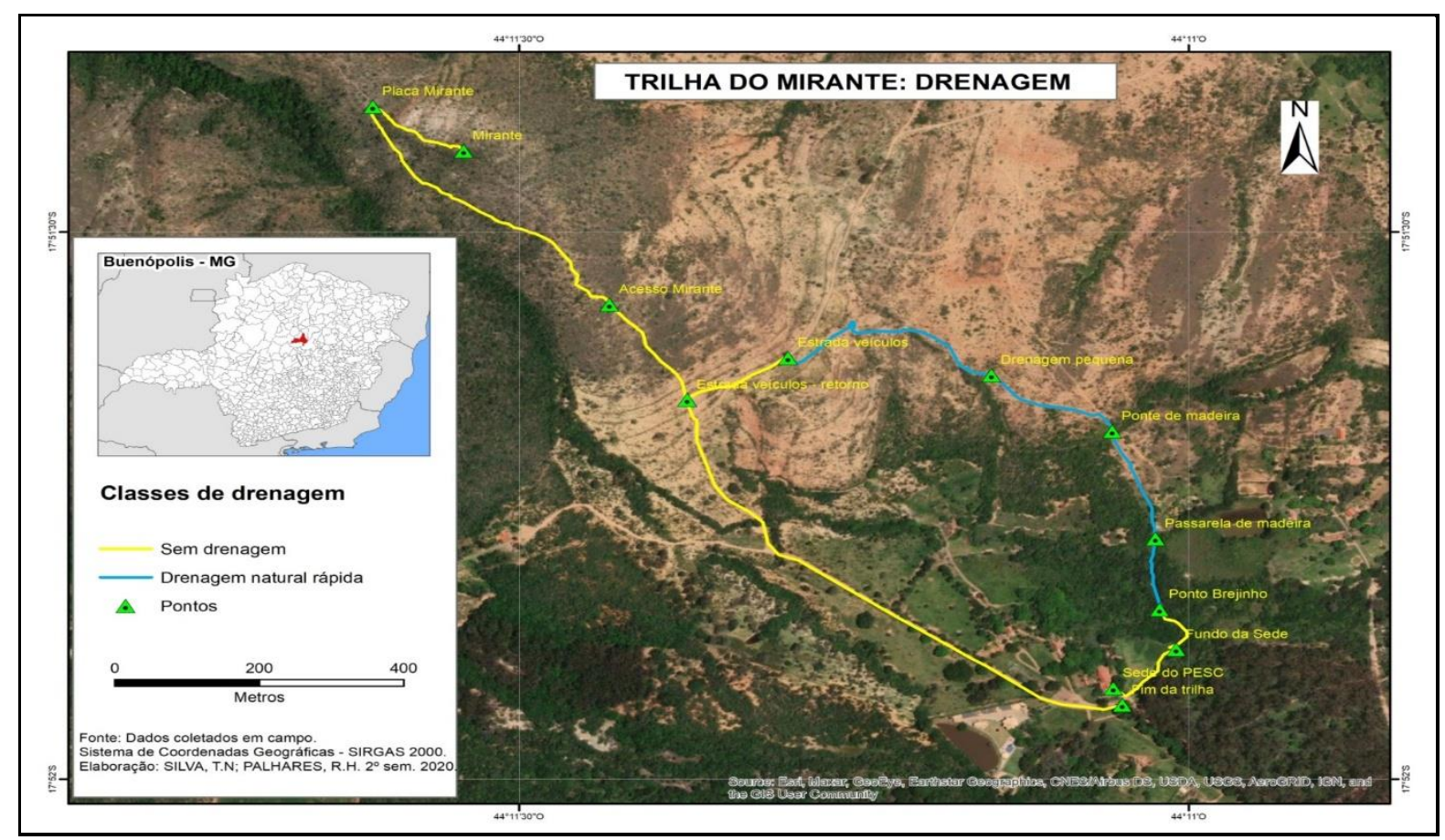

Fonte: Elaborado pelos autores

Para a elaboração da carta imagem do grau de dificuldade da trilha do Mirante, foi utilizado a sobreposição de todos os valores levantados pelos critérios anteriores (declividade, estrutura do terreno, vegetação e drenagem) e criado uma escala de classificação conforme o resultado cruzado entre os indicativos. Logo, os critérios de valores ficaram definidos da seguinte forma: declividade $50 \%$, vegetação $30 \%$, estrutura do terreno $15 \%$ e vegetação $5 \%$.

O produto final (Figura 12) expõe cores distintas por trechos, de acordo com as classes definidas anteriormente. Percebe-se que boa parte da trilha apresenta um nível de dificuldade moderado ou difícil. Esse cenário se justifica por dois aspectos: primeiro pelos pontos com inclinação alta e segundo pelos trechos sem vegetação, levando o visitante a ficar mais tempo exposto ao sol. 
SILVA, T.N; PALHARES, R.H

Parque Estadual Serra do Cabral em Minas Gerais: classificação do grau de dificuldade da trilha do mirante

Figura 12 - Carta Imagem: Grau de Dificuldade - Trilha do Mirante

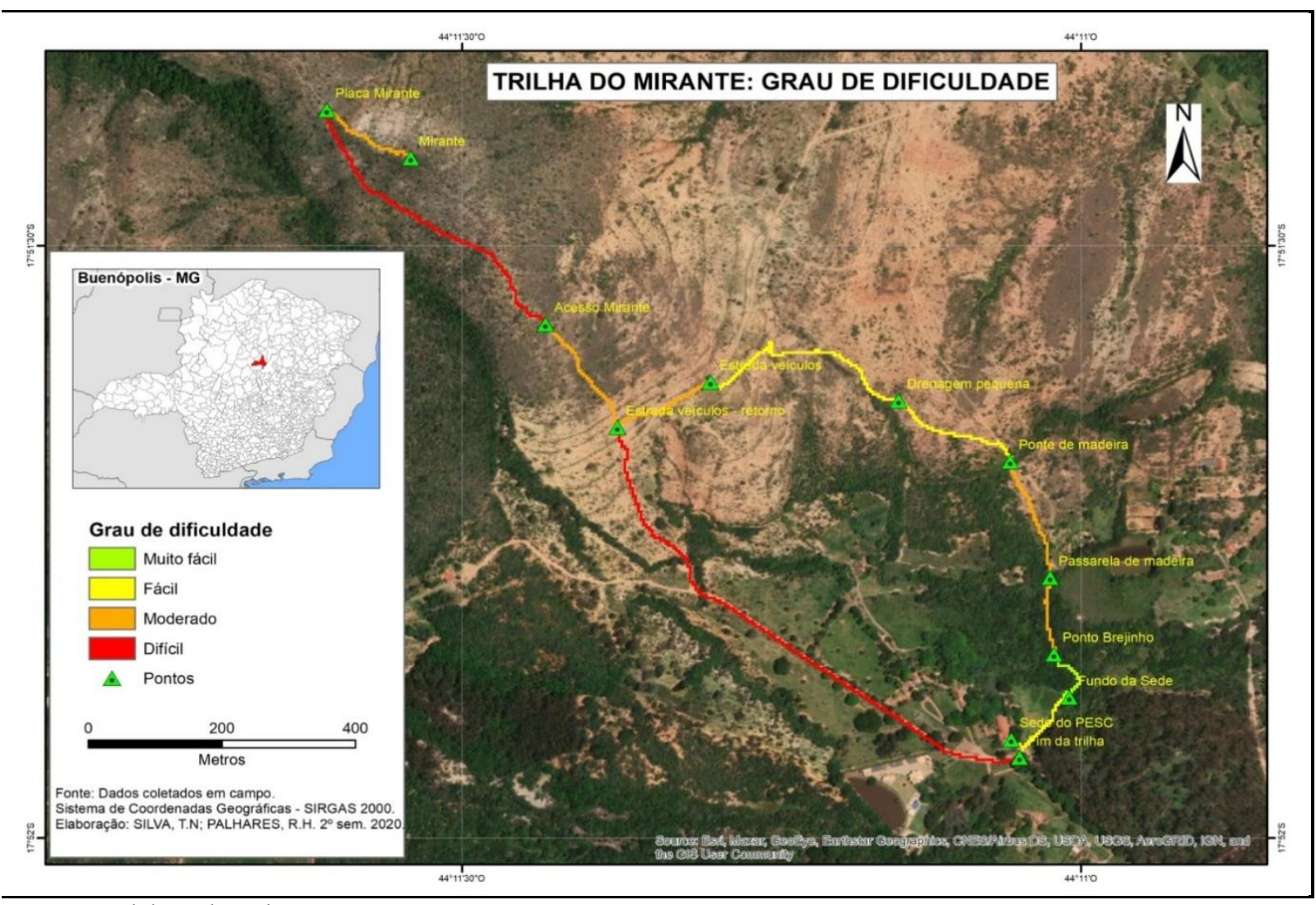

Fonte: Elaborado pelos autores

Utilizando o método do cálculo matemático, que são a soma das distâncias entre os pontos associadas com as suas caraterísticas, foi possível determinar a porcentagem do grau de dificuldade de cada trecho do percurso, conforme tabela 2.

Tabela 2 - Medição do Grau de dificuldade da trilha por distância

\begin{tabular}{c|c|c}
\hline Classificação & Distância (metros) & Porcentagem \% \\
\hline Muito Fácil & 87 & $3 \%$ \\
\hline Fácil & 654 & $18 \%$ \\
\hline Moderado & 1.299 & $35 \%$ \\
\hline Difícil & 1.671 & $45 \%$ \\
\hline
\end{tabular}

Fonte: Elaborado pelo autor.

Contudo, no instante que a carta imagem contendo o grau de dificuldade puder ser visto pelo visitante, acredita-se que a trilha irá possibilitar que o turista certifique as suas possibilidades físicas e decida ou não em realizar o percurso da trilha. Essas informações serão úteis para contribuir no planejamento e gestão dessa trilha pela gestão do parque e na atualização do plano de manejo. Além disso, as estruturas existentes em todo o trajeto como 
SILVA, T.N; PALHARES, R.H

Parque Estadual Serra do Cabral em Minas Gerais: classificação do grau de dificuldade da trilha do mirante pontes, sinalização e o deque de madeira na parte mais alta trilha, ajudam a equilibrar o seu grau de dificuldade.

\section{CONSIDERAÇÕES FINAIS}

Percebe-se que a principal colaboração do trabalho foi promover de maneira detalhada a classificação do grau de dificuldade da trilha do Mirante, utilizando uma análise físico-espacial por cada trajeto. Esse tipo de leitura poderá oferecer aos gestores do PESC um valioso instrumento de diagnóstico referente a diversidade da trilha e suas principais características. Além disso, ficou perceptivo através dos resultados alcançados que os critérios utilizados (declividade, vegetação, estrutura do terreno e drenagem), somados com os recursos do SIG, irá auxiliar nas estratégias de ampliação do seu uso público.

E por fim, ressalta-se que a visitação turística em unidades de conservação ainda se apresenta como um aspecto vulnerável e que na maioria dos casos são realizados sem um planejamento adequado comprometendo a segurança do visitante, o espaço natural e a conservação dos parques. Portanto, espera-se que esse estudo sobre a classificação do grau de dificuldade da Trilha do Mirante possa servir como referência para outras ações e ser utilizado em outras trilhas do parque, ampliando assim, a utilização dos seus atrativos de maneira responsável e que promova uma experiência agradável ao seu visitante.

\section{AGRADECIMENTOS}

Ao Instituto Estadual de Floresta de Minas Gerais (IEF) e a toda equipe do Parque Estadual Serra do Cabral pelo apoio logístico e humano para a realização do levantamento de campo.

\section{REFERÊNCIAS}

ABNT - ASSOCIAÇÃO BRASILEIRA DE NORMAS TÉCNICAS. NBR 15505-2. Turismo com atividades de caminhada Parte 2: Classificação de percursos. Brasil: ABNT, 2008.

ANDRADE, W. J. Implantação e manejo de trilhas. In: MITRAUD, S. (Ed.). Manual de ecoturismo de base comunitária: ferramentas para um planejamento responsável. Brasília: WWF. p. 247- 259. 2003

ANDRADE, W. J. Manejo de trilhas para o ecoturismo. In: NEIMAN, Z. \& MENDONÇA, R. Ecoturismo no Brasil. São Paulo: Manole. 2005. 
Parque Estadual Serra do Cabral em Minas Gerais: classificação do grau de dificuldade da trilha do mirante

ARGENTINA - MINISTERIO DE TURISMO. Manual de Producto: Senderos de Argentina - Huella Andina. Plan Federal Estratégico de Turismo Sustentable 2016 PFETS. Subsecretaria de Desarrollo Turístico. Setiembre 2010. Argentina: Ministerio de Turismo, Presidencia de la Nación, 2010. 168 p.

BRASIL. Lei $\mathbf{n}^{0}$ 9.985, de 18 de julho de 2000. Regulamenta o art. 225, § 1o, incisos I, II, III e VII da Constituição Federal, institui o Sistema Nacional de Unidades de Conservação da Natureza e dá outras providências. Brasília: Presidência da República, Casa Civil, 2000.

CÂMARA, G.; DAVIS, C.; MONTEIRO, A. M. V. Introdução à ciência da geoinformação. São José dos Campos: Ministério da Ciência e Tecnologia, Instituto Nacional de Pesquisas Espaciais, 2001.

COSTA, F. R. Turismo para todos: Turismo Social no Sesc-SP. São. Paulo: Sesc. EESC European Economic and Social Committee. Opinion of the Economic and Social Committee on Social Tourism in Europe. Brussels: EESC, 2006.

COTES, M. et al. Avaliação do nível de dificuldade da trilha interpretativa do Ecoparque de Una (BA): aspectos físicos, biológicos e parâmetros de esforço físico dos visitantes. Revista Brasileira de Ciências do Esporte, [S./l.], v. 28, n. 3, p. 191-207, 2007.

DAMBRÓS, Gabriela. Qual o papel das geotecnologias na estruturação de um novo paradigma da Geografia? Caderno de Geografia, [S./l.], v.30, n.60, jan-mar 2020. Disponível em: 〈http://periodicos.pucminas.br/index.php/geografia/article/view/22325>. acesso em jun. de 2020.

\section{EMBRAPA - EMPRESA BRASILEIRA DE PESQUISA AGROPECUÁRIA. Serviço} Nacional de Levantamento e Conservação de Solos (Rio de Janeiro, RJ). Súmula das 10. Reunião Técnica de Levantamento de Solos. Rio de Janeiro, 1979. 83p. (EMBRAPA-SNLCS. Micelânea, 1)

FEMERJ - FEDERAÇÃO DE MONTANHISMO DO ESTADO DO RIO DE JANEIRO. Metodologia de Classificação de Trilhas v.6.1. Junho de 2016. Disponível em: $\langle$ http://femerj.org/images/arquivos/classificacao-trilhas-v5.0.pdf $>$. Acesso em: 08 jul. 2020.

FLORENZANO, T. G. Geotecnologias na geografia aplicada: difusão e acesso. Revista do Departamento de Geografia, São Paulo, n. 17, P. 24-29, 2005.

HUGO, M. L. Energy equivalent as a measure of the difficulty rating of hiking trails. Tourism Geographies: an international journal of tourism space, place and environment, [S./1.], v. 1, n. 3, p. 358-373, 1999.

GOVERNO DO ESTADO DE MINAS GERAIS. Instituto Estadual de Florestas (IEF). 2020. Disponível em: http://www.ief.mg.gov.br/unidades-de-conservacao/parques-de-minas. acesso em: 15 de jul. 2020.

KINKER, S. Ecoturismo e conservação da natureza em parques nacionais. Campinas, SP: Papirus, 2002. 224 p. (Coleção Turismo). 
SILVA, T.N; PALHARES, R.H

Parque Estadual Serra do Cabral em Minas Gerais: classificação do grau de dificuldade da trilha do mirante

HAMOY, Juliana Azevedo. Turismo em unidades de conservação e o desenvolvimento local em Soure- PA. 2018. 199 f. Dissertação (Mestrado - Programa de Pós-Graduação em Desenvolvimento Sustentável do Trópico Úmido), Universidade Federal do Pará, Pará, 2018.

MAGRO, T. C. Impactos do uso público em uma trilha no planalto do Parque Nacional do Itatiaia. 1999. 135 f. Tese (Doutorado em Ciências da Engenharia Ambiental) - Escola de Engenharia de São Carlos, Universidade de São Paulo, São Carlos, 1999.

MARTINELLI, M. Mapas da geografia e cartografia temática. 4. ed. São Paulo, SP: Contexto, 2008.

MENEZES, P. M. L.; FERNANDES, M. C. Roteiro de Cartografia. São Paulo, SP: Oficina de Textos, 2013. 288 p.

MIRANDA, J. I. Fundamentos de sistemas de informações geográficas. 2. ed. Rev. Atual Brasília, Brasília- DF: Embrapa, Informação Tecnológica, 2010. 425 p.

OLIVEIRA, Renata Teixeira; BLOOMFIELD, Vanessa Kelva; MAGALHÃES, Luis Mauro Sampaio. Trilhas Auto-guiadas: proposta de implantação e interpretação na Floresta Nacional Mário Xavier Sandra Regina da Costa. rev. Floresta e Ambiente, Rio de Janeiro. v. 6, n.1, pag. 138-143 jan./dez. 1999. Disponível em:

<http://www.geocities.ws/floramrural/p0138.pdf>. Acesso em: 16 de ago.2020.

OSÓRIO, Bruno Manuel da Silva. Aplicação dos Sistemas de Informação Geográfica ao Turismo na Natureza: Concepção de Percursos Pedestres para o Concelho de Lamego. 2010. 102 f. Dissertação (Mestrado em Sistemas de Informação Geográfica e Modelação Territorial Aplicados ao Ordenamento), Universidade de Lisboa Instituto de Geografia e Ordenamento do Território. Lisboa, Portugal 2010.

PIMENTEL, Douglas de Souza. Parcerias para a gestão do uso público em parques. Anais... I Encontro Fluminense - Uso Público em Unidades de Conservação. Universidade Federal Fluminense (UFF), Niterói - RJ, v.1, n.1, p. 27-38, 2013. Disponível em <https://www.researchgate.net/publication/282669434_Uso_publico_em_unidades_de_conser

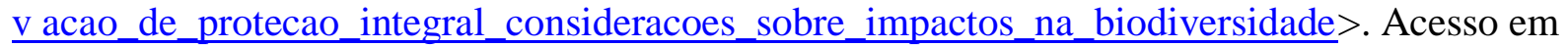
10 de jun. 2020.

RYLANDS, Anthony B.; BRANDON, Katrina. Unidades de Conservação brasileiras. rev. Megadiversidade, Belo Horizonte, v. 1, n. 1, p. 27-35, jul. 2005. Disponível em: https://d3nehc6yl9qzo4.cloudfront.net/downloads/conservation_units.pdf acesso em: 09 de jun. de 2020.

SALOMÃO, F.X.T. Controle e prevenção dos Processos Erosivos. In GUERRA, A.J.T.; SILVA, A.S.; BOTELHO, R.G.M. (orgs) 1999. Erosão e Conservação dos Solos: Conceitos, Temas e Aplicações. Rio de Janeiro: Bertrand Brasil, 340p.

SERRANO, C. M. de T.; BRUHNS, H. T. Viagens à natureza: turismo, cultura e ambiente. Campinas, SP: Papirus, 1997. 
Parque Estadual Serra do Cabral em Minas Gerais: classificação do grau de dificuldade da trilha do mirante

SILVA, Grislayne Guedes Lopes da. Classificação do grau de dificuldade de trilhas : uso de geotecnologias na elaboração de um modelo aplicado ao Parque Nacional do Itatiaia, Brasil. 2016. 210 f. Dissertação (Mestrado em Ciências), Programa de Pós Graduação em Turismo, Escola de Artes, Ciências e Humanidades, Universidade de São Paulo, São Paulo 2016.

TAKAHASHI, L. Y. Uso público em Unidades de Conservação. Cadernos de Conservação. Paraná: Fundação O Boticário de Proteção à Natureza, ano 02, out.2004.

VALLEJO, L.R., PIMENTEL, D.S., MONTEZUMA, R.C.M.(Orgs.). Uso Público em Unidades de Conservação: planejamento, turismo, lazer, educação e impactos. Artigos do $1^{\circ}$ e $2^{\circ}$ Encontros Fluminenses - 2013 e 2015. Niterói: Ed. Alternativa, 2015.

\section{Autores}

Thiago Neves Silva - É Graduado em Turismo e Hotelaria pela Faculdades Integradas Pitágoras (FIP-MOC). Atualmente é Mestrando pelo Programa de Pós Graduação em Geografia (PPGEO) da Universidade Estadual de Montes Claros (UNIMONTES).

Ricardo Henrique Palhares - É Graduado, Mestre e Doutor em Geografia pela Pontifícia Universidade Católica de Minas Gerais (PUC/Minas). Atualmente é Professor do Departamento de Geociências e do Programa de Pós-Graduação em Geografia da Universidade Estadual de Montes Claros - PPGEO/UNIMONTES.

Artigo recebido em: 19 de novembro de 2020.

Artigo aceito em: 19 de dezembro de 2020.

Artigo publicado em: 22 de dezembro de 2020. 